\title{
Hidrocondicionamento e armazenamento de sementes de melão
}

\section{Hydropriming and storage of melon seeds}

\author{
Maria Aparecida de Medeiros ${ }^{1}$; Salvador Barros Torres ${ }^{2 *}$; \\ Maria Zuleide de Negreiros ${ }^{2}$; José Antônio da Silva Madalena ${ }^{1}$
}

\section{Resumo}

A técnica de hidratação controlada das sementes vem sendo utilizada como método de condicionamento fisiológico objetivando melhorar o desempenho destas no campo. O trabalho teve por objetivo avaliar o efeito do hidrocondicionamento fisiológico de sementes de melão durante o armazenamento. Foram realizados testes de germinação, primeira contagem de germinação, emergência de plântulas em casa de vegetação e envelhecimento acelerado. Utilizaram-se quatro lotes de sementes de melão de dois híbridos, Imperial e Gaúcho. O condicionamento fisiológico foi avaliado durante os períodos de armazenamentos de $0,30,60$ e 90 dias, sob condições controladas de $15^{\circ} \mathrm{C}$ e $45 \%$ UR. As sementes condicionadas de melão e armazenadas por 90 dias apresentam resultados superiores de germinação, primeira contagem de germinação, emergência de plântulas e envelhecimento acelerado quando comparadas com as sementes que não foram submetidas a esse tratamento. $\mathrm{O}$ armazenamento de sementes de melão em condições controladas $\left(15^{\circ} \mathrm{C}\right.$ e $45 \%$ UR) permite a manutenção dos efeitos benéficos do hidrocondicionamento pelo período de 90 dias.

Palavras-chave: Cucumis melo L., testes de vigor, germinação

\begin{abstract}
The technique of controlled hydration of the seeds has been used as method of physiologic conditioning aiming at to improve the acting of these in the field. The study aimed to evaluate the effect of physiological hydropriming during storage of melon seeds. The evaluations were germination, first count germination, seedling emergence under greenhouse conditions and accelerated aging. We used two hybrids, Imperial and Gaucho, each comprising four seed lots. The priming was assessed during the periods of storage at 0, 30, 60 and 90 days, under controlled conditions of $15^{\circ} \mathrm{C}$ and $45 \%$ UR. Primed seeds of melons stored for 90 days showed better results for standard germination, first count germination, emergence and accelerated aging when compared with seeds that were not subjected to this treatment. Storage of melon seeds under controlled conditions $\left(15^{\circ} \mathrm{C}\right.$ and $\left.45 \% \mathrm{UR}\right)$ allows for the maintenance of the beneficial effects of hydropriming for 90 days.
\end{abstract}

Key words: Cucumis melo L., vigor tests, germination

1 Profs. Drs., Instituto Federal de Alagoas, IFAL, Satuba, AL. E-mail: aparecidacn@gmail.com; jasmufal@gmail.com

2 Profs. Drs., Universidade Federal Rural do Semi-Árido, UFERSA, Dept ${ }^{\circ}$ de Ciências Vegetais, Mossoró, RN. E-mail: sbtorres@ ufersa.edu.br; zuleide@ufersa.edu.br

* Autor para correspondência 


\section{Introdução}

A produção anual brasileira de melão (Cucumis melo L.) foi de 380 mil toneladas, obtida por meio do cultivo em 14,9 mil hectares, sendo a região Nordeste responsável por 94,3\% desta produção (IBGE, 2012). O Brasil é, atualmente, um dos maiores produtores de melão da América do Sul, com $17 \%$ da produção total (COSTA, 2008).

As sementes de melão, por apresentarem alto valor comercial, merecem atenção especial quanto ao potencial fisiológico. Entretanto, para esta espécie, ainda são poucas as pesquisas direcionadas à comparação de técnicas de condicionamento das sementes visando à melhoria do seu desempenho no campo, sobretudo nas condições em que são produzidas no País (PAIVA et al., 2012; AMARO et al., 2014).

Diante do cenário de sementes de hortaliças tanto nacional como mundial, não basta produzir sementes, mas é importante garantir sua qualidade e desempenho. Essa melhoria no desempenho da semente pode ser obtida através da técnica do condicionamento fisiológico das sementes, sendo a prática do hidrocondicionamento uma das utilizadas.

O hidrocondicionamento é um tratamento pré-germinativo que consiste na imersão das sementes em água por um determinado período a uma temperatura pré-estabelecida para regular a quantidade de água absorvida pela semente, promovendo as fases I e II da germinação, mas sem permitir o estádio de protrusão da raiz primária, cuja paralisação da embebição deve ocorrer antes deste evento (POSSE et al., 2002).

Quando uma semente absorve água, desencadeia uma série de mudanças fisiológicas e bioquímicas no embrião, a emissão da raiz primária sinaliza o início da fase III da curva de embebição e quando as sementes atingem essa fase ocorre perda da tolerância à desidratação (BEWLEY; BLACK, 1994). Portanto, a determinação do teor de água após o condicionamento fisiológico deve ser considerada um importante parâmetro na seleção do melhor procedimento para realização deste (CASEIRO; BENNETT; MARCOS FILHO, 2004).

Vários fatores estão envolvidos na eficiência do condicionamento fisiológico: o genótipo, o grau de deterioração da semente, o período de tratamento, a temperatura, o tamanho das sementes, a velocidade de absorção de água, o grau de hidratação alcançado pelas sementes e suas partes, a aeração a secagem após o tratamento, o número de ciclos de hidratação/secagem, as condições e o período de armazenamento (MARCOS FILHO, 2005).

Desse modo, resultados positivos do condicionamento osmótico foram mais pronunciados para sementes de melão de baixo potencial fisiológico (NASCIMENTO; ARAGÃO, 2004). Os lotes que apresentam maior resposta ao condicionamento são aqueles que possuem baixa percentagem de germinação e germinação lenta, como resultado do envelhecimento.

Após o condicionamento fisiológico, as sementes atingem teores de água relativamente elevados e inadequados para a conservação do potencial fisiológico durante o armazenamento (ARAÚJO et al., 2011). Dessa forma, a secagem deve ser conduzida de maneira adequada, para minimizar a possibilidade de reversão dos efeitos benéficos do tratamento (MARCOS FILHO; KIKUTI, 2008).

Relatos da reversão dos efeitos benéficos do hidrocondicionamento foram verificados por Caseiro, Bennett e Marcos Filho (2004), com sementes de cebola; Marcos Filho e Kikuti (2008) e Kikuti e Marcos Filho (2009), com sementes de couve-flor; Pereira et al. (2009), com sementes de cenoura; Araújo et al. (2011), com sementes de maxixe; Paiva et al. (2012), com sementes de melão. No entanto, outros autores como Barbedo, Marcos Filho Novembre(1997)e Caseiro, Bennette Marcos Filho (2004) verificaram que o comportamento das sementes depende do genótipo, dos métodos utilizados para o tratamento e das condições de armazenamento. Desta maneira, a secagem deve ser conduzida de maneira adequada, para minimizar a 
possibilidade de reversão dos efeitos benéficos do tratamento (MARCOS FILHO; KIKUTI, 2008). Além disso, segundo Balbino e Lopes (2006), a secagem após o hidrocondicionamento é desejável, pois evita expor as sementes aos riscos de danos mecânicos provocados pelos equipamentos de semeadura.

Os efeitos do condicionamento sobre o potencial de armazenamento podem ser distintos de acordo com a espécie (CHIU; CHEN; SUNG, 2002). Nesse sentido, sementes de alface condicionadas apresentaram maior velocidade de germinação que as não condicionadas, mas tornaram-se suscetíveis à deterioração no armazenamento (TARQUIS; BRADFORD, 1992). No entanto, sementes de tomate submetidas ao condicionamento, apresentaram maior potencial de armazenamento que às não condicionadas (ROSSETTO; LIMA; NAKAGAWA, 2002).

O objetivo deste trabalho foi avaliar a qualidade fisiológica de sementes de melão hidrocondicionadas durante o armazenamento.

\section{Material e Métodos}

O experimento foi realizado no Laboratório de Análise de Sementes e em Casa de Vegetação do Departamento de Ciências Vegetais da Universidade Federal Rural do Semi-Árido (UFERSA), em Mossoró - RN, entre setembro e dezembro de 2011. Utilizaram-se sementes de melão, híbridos Imperial e Gaúcho (fornecidas pela empresa ISLA Sementes Ltda.), sendo cada híbrido representado por quatro lotes.

Em todo o período experimental, as sementes foram mantidas em suas embalagens originais (latas) e armazenadas em ambiente controlado $\left(15^{\circ} \mathrm{C}\right.$ e $45 \%$ UR).

Os quatro lotes de cada material foram homogeneizados e avaliados quanto à marcha de absorção de água, seguido de hidrocondicionamento com posterior secagem das sementes por tempo suficiente para que as sementes atingissem a umidade do início do teste. Os testes foram realizados com a quantidade de sementes suficiente para serem utilizadas nas avaliações das quatro épocas de armazenamento (0, 30, 60 e 90 dias).

Curva de absorção de água: foi conduzido segundo procedimento descrito por Caseiro, Bennett e Marcos Filho (2004), empregando-se 20 sementes de cada lote que foram colocadas entre duas camadas de três folhas de papel toalha, umedecidas com água em quantidade equivalente a 2,5 vezes o peso seco do papel e colocadas para embeber a $20^{\circ} \mathrm{C}$. A marcha de absorção foi monitorada por meio de pesagens sucessivas das sementes em intervalos de 60 minutos até que ocorresse a protrusão da raiz primária. Esta foi considerada quando pelo menos cinco sementes apresentavam a raiz primária com comprimento mínimo de $1 \mathrm{~mm}$. A taxa de embebição foi calculada com base no peso inicial das sementes.

Hidrocondicionamento: as sementes foram colocadas para embeber entre duas camadas de folhas de papel toalha, umedecidas com quantidade de água equivalente a 2,5 vezes o seu peso seco do papel. Neste procedimento, as sementes foram mantidas a $20^{\circ} \mathrm{C}$, até atingirem grau de umidade próximo a emissão da radícula. Em seguida, as sementes foram retiradas do substrato e submetidas à secagem superficial (sobre papel toalha) até atingirem a umidade inicial, para posterior armazenamento. A taxa de embebição foi calculada com base no peso inicial das sementes, conforme fórmula, descrita por Hampton e TeKrony (1995), $\mathrm{P} 2=[(100-\mathrm{A}) /(100-\mathrm{B})] \times \mathrm{P} 1$. Em que: $\mathrm{A}=$ teor de água inicial da semente (base úmida); $\mathrm{B}=$ teor de água desejado; $\mathrm{P} 1$ = peso inicial da semente $(\mathrm{g})$; P2 $=$ peso final da semente $(\mathrm{g})$.

Armazenamento: após a retirada das sementes da câmara Biochemical Oxygen Demand (B.O.D.), elas foram colocadas sobre papel toalha em bancada à temperatura ambiente média de $30^{\circ} \mathrm{C}$, por 12 horas, o suficiente para atingirem o grau de umidade inicial para o armazenamento. Em seguida, as 
sementes foram condicionadas em sacos de plástico hermeticamente fechados e armazenadas em ambiente controlado de 18 - 20\% e $45 \%$ de umidade relativa do ar. As sementes foram avaliadas no tempo zero 0, 30, 60 e 90 dias de armazenamento, através das seguintes avaliações: Grau de umidade (GU): determinado pelo método da estufa a $105 \pm 3^{\circ} \mathrm{C}$ durante 24 h (BRASIL, 2009), utilizando-se duas subamostras para cada lote, com 20 sementes cada. Os resultados foram expressos em percentagem média para cada lote (base úmida). Germinação (G): realizada com quatro repetições de 50 sementes por tratamento, semeadas sobre folhas de papel toalha, em forma de rolos, umedecidas com quantidade de água equivalente a 2,5 vezes o peso do substrato seco (MENEZES; SILVEIRA; STORCK, 1993), colocadas em germinador a 25 ${ }^{\circ} \mathrm{C}$. A contagem das plântulas normais foi realizada aos quatro e oito dias após a instalação do teste, segundo os critérios estabelecidos pelas Regras para Análise de Sementes (BRASIL, 2009), e os resultados expressos em percentagem média de plântulas normais. Primeira contagem de germinação (PCG): obtida juntamente com o teste de germinação, pela contagem de plântulas normais, aos quatro dias após a semeadura (BRASIL, 2009). Envelhecimento acelerado (EA): realizou-se de acordo com a metodologia descrita por Marcos Filho (1999), utilizando-se caixas plásticas $(11 \times 11 \times 3 \mathrm{~cm})$, tipo gerbox, no interior de cada compartimento individual foram adicionados 40 $\mathrm{mL}$ de água, sob uma tela metálica onde ficaram acondicionadas as sementes, tampadas e colocadas em câmara do tipo câmara B.O.D. Utilizaram-se amostras de 250 sementes por lote, distribuídas de maneira a formarem uma camada uniforme sobre a superfície da tela metálica suspensa no interior de cada caixa plástica. As caixas, tampadas, permaneceram no interior da câmara durante três períodos de envelhecimento (48, 72 e $96 \mathrm{~h}$ ), sendo utilizadas duas temperaturas $\left(38^{\circ} \mathrm{C}\right.$ e $\left.41^{\circ} \mathrm{C}\right)$. Em seguida, as sementes foram submetidas ao teste de germinação com as avaliações realizadas aos quatro dias após a semeadura e, os resultados, expressos em percentagem média de plântulas normais. Para fins de monitoramento do teste, foi determinado, o grau de umidade das sementes antes e após os períodos de incubação (BRASIL, 2009). Emergência de plântulas em casa de vegetação $(\mathrm{E})$ : conduzida em casa de vegetação à temperatura ambiente média de $30^{\circ} \mathrm{C}$, utilizou-se quatro repetições de 50 sementes por tratamento, semeadas em bandejas de poliestireno expandido, com 128 células, contendo substrato comercial plantmax ${ }^{\circledR}$. As contagens foram efetuadas aos 12 dias após a semeadura, expressando-se os resultados em percentagem de plântulas normais (NAKAGAWA, 1994).

A análise estatística dos dados foi realizada considerando-se separadamente cada híbrido e teste conduzido. Utilizou-se o delineamento inteiramente casualizado, com quatro repetições e tratamento dispostos em fatorial 4 x 4 (quatro épocas de avaliação e quatro lotes para cada híbrido). Os resultados foram submetidos à análise de variância e regressão. As médias foram comparadas pelo teste e Tukey, a 5\% de probabilidade, utilizandose o programa SISVAR for Windows versão 4.1 (FERREIRA, 2011).

\section{Resultados e Discussão}

O teor de água necessário para emissão da raiz primária variou de acordo com o híbrido e o lote avaliado. Assim, a emissão da raiz primária das sementes do híbrido Imperial iniciou quando as mesmas apresentaram teor de água de 42,9\% referente ao lote 3 e 45,9\% referente ao lote 1, após 52 horas de embebição. Para as sementes do híbrido Gaúcho, a protrusão ocorreu em sementes com teor de água entre $36,2 \%$ no lote 4 a $40,3 \%$ no lote 1 , após 47 horas de embebição. Gurgel Júnior et al. (2009), trabalharam com pepino e observaram que as sementes dessa espécie necessitaram de apenas de 26 horas de embebição para emitirem a protrusão da radícula, com um grau de umidade de 43,5\% (Tabela 1). 
Tabela 1. Grau de umidade (\%) de lotes de sementes de melão, híbridos Imperial e Gaúcho, durante a marcha de absorção de água a $20^{\circ} \mathrm{C}$.

\begin{tabular}{|c|c|c|c|c|c|c|c|c|}
\hline \multirow{3}{*}{$\begin{array}{l}\text { Período de embebição } \\
\text { (h) }\end{array}$} & \multicolumn{8}{|c|}{ Híbridos/Lotes } \\
\hline & \multicolumn{4}{|c|}{ Imperial } & \multicolumn{4}{|c|}{ Gaúcho } \\
\hline & 1 & 2 & 3 & 4 & 1 & 2 & 3 & 4 \\
\hline 0 & 6,4 & 6,4 & 6,8 & 6,9 & 6,5 & 6,6 & 6,3 & 6,7 \\
\hline 1 & 21,0 & 28,1 & 23,2 & 23,4 & 21,2 & 21,2 & 19,3 & 19,9 \\
\hline 3 & 26,2 & 31,9 & 26,6 & 25,3 & 24,1 & 23,8 & 21,7 & 21,5 \\
\hline 5 & 30,1 & 34,6 & 29,7 & 29,1 & 26,1 & 26,5 & 24,1 & 24,0 \\
\hline 7 & 32,7 & 36,8 & 30,9 & 31,7 & 28,7 & 28,6 & 26,6 & 26,3 \\
\hline 9 & 34,0 & 38,1 & 31,8 & 32,9 & 29,9 & 29,4 & 27,7 & 27,4 \\
\hline 11 & 35,2 & 38,7 & 32,7 & 33,7 & 30,3 & 30,5 & 28,5 & 27,9 \\
\hline 13 & 35,6 & 38,9 & 33,4 & 34,2 & 30,8 & 31,1 & 29,1 & 28,9 \\
\hline 15 & 36,8 & 39,3 & 34,8 & 35,3 & 31,5 & 32,0 & 29,5 & 29,3 \\
\hline 17 & 37,7 & 39,8 & 35,5 & 35,9 & 32,4 & 32,8 & 30,3 & 29,9 \\
\hline 19 & 38,4 & 40,1 & 36,3 & 36,6 & 33,2 & 33,3 & 30,7 & 30,5 \\
\hline 21 & 39,1 & 40,7 & 36,9 & 37,0 & 34,1 & 34,2 & 31,1 & 30,8 \\
\hline 23 & 39,4 & 40,9 & 37,4 & 37,4 & 34,4 & 34,6 & 31,5 & 31,3 \\
\hline 25 & 39,9 & 41,7 & 38,3 & 38,1 & 35,4 & 35,2 & 32,2 & 31,6 \\
\hline 27 & 40,3 & 42,0 & 38,5 & 38,3 & 35,8 & 35,6 & 32,5 & 32,1 \\
\hline 29 & 41,2 & 42,9 & 38,6 & 38,8 & 36,3 & 36,0 & 32,5 & 32,5 \\
\hline 31 & 41,5 & 43,0 & 39,0 & 39,8 & 37,0 & 36,4 & 32,9 & 32,7 \\
\hline 33 & 42,0 & 43,8 & 39,1 & 39,8 & 37,0 & 36,4 & 33,3 & 32,7 \\
\hline 35 & 42,4 & 43,9 & 39,1 & 39,9 & 37,9 & 36,7 & 33,3 & 33,1 \\
\hline 37 & 42,4 & 44,0 & 39,8 & 39,9 & 37,9 & 36,7 & 33,3 & 33,1 \\
\hline 47 & 44,8 & 45,1 & 41,3 & 41,4 & 40,3 & 38,9 & 37,7 & 36,2 \\
\hline 52 & 45,9 & 45,7 & 42,9 & 44,1 & ---- & -- & -- & --- \\
\hline
\end{tabular}

Grau de umidade no início da emissão da raiz primária (quando cinco ou mais sementes emitiram raiz primária com, no mínimo, $1 \mathrm{~mm}$ de comprimento).

Fonte: Elaboração dos autores.

Deve-se destacar que entre os lotes de sementes do híbrido Imperial a diferença de absorção entre os lotes foi de 3,0 pontos percentuais, enquanto que para o híbrido Gaúcho essa diferença foi de 4,1\%. Para ambos os híbridos, não foi possível correlacionar essa absorção de água ao vigor dos lotes. No entanto, pode-se dizer que o híbrido Imperial necessitou de uma maior quantidade de água, assim como demorou mais tempo para emitir a protrusão da raiz primária.

Desta forma, os graus de umidade finais ao serem atingidos com o condicionamento fisiológico pelos híbridos foram fixados em $20 \%$, para garantir que o condicionamento das sementes fosse paralisado ainda na fase II do processo de germinação, ou seja, ativando o metabolismo, mas evitando a protrusão da raiz primária, já que se trata da fase mais longa e com o ganho de umidade mais lento. De acordo com Bewley e Black (1994), é necessária uma diminuição da absorção de água para a mobilização das substâncias que foram desdobradas na fase I da germinação, da região de reserva para os tecidos meristemáticos. Nesse sentido, ainda segundo os mesmos autores, as sementes de baixo potencial fisiológico precisam de maior tempo para reorganizar suas membranas e alcançar o início da fase III do processo de germinação.

Para a avaliação do desempenho das sementes armazenadas, o grau de umidade foi avaliado antes das sementes terem sido submetidas ao tratamento 
de condicionamento fisiológico, variando de 6,3 a 6,7\%. Assim como, imediatamente após o condicionamento de $20 \mathrm{~h}$ de embebição das sementes, com resultados entre 29,8 e $38,0 \%$, não foi observado protrusão da radícula durante $o$ condicionamento (Tabela 2). A absorção de água pelas sementes de melão durante o condicionamento osmótico, referentes às duas primeiras fases, seguiu o clássico padrão trifásico (BEWLEY; BLACK, 1994). Com uma rápida absorção de água observada na primeira hora de embebição, correspondentes a I fase, seguido pela II fase, que ocorre mais lentamente marcadamente estendida pelo condicionamento osmótico; este tratamento previne a semente de iniciar a fase III de protrusão da radícula.

Tabela 2. Grau de umidade inicial e após $20 \mathrm{~h}$ de embebição, seguido de $12 \mathrm{~h}$ de secagem à temperatura ambiente (média de $30^{\circ} \mathrm{C}$ ) e, após $0,30,60$ e 90 dias de armazenamento de lotes de sementes de melão, híbridos Imperial e Gaúcho.

\begin{tabular}{ccccccccc}
\hline \multirow{2}{*}{ Híbrido } & Lote & Inicial & $\begin{array}{c}\text { Após 20h } \\
\text { embebição }\end{array}$ & $\begin{array}{c}\text { Após 12h } \\
\text { secagem }\end{array}$ & \multicolumn{3}{c}{ Armazenamento (dias) } \\
\cline { 4 - 8 } Imperial & 1 & 6,4 & 38,0 & 6,6 & 6,5 & 6,0 & 6,0 & 4,8 \\
& 2 & 6,4 & 37,9 & 6,5 & 6,4 & 4,8 & 4,3 & 4,0 \\
& 3 & 6,8 & 34,9 & 6,6 & 6,3 & 5,9 & 5,7 & 5,5 \\
& 4 & 6,6 & 35,3 & 6,8 & 6,5 & 5,0 & 5,2 & 5,0 \\
\multirow{3}{*}{ Gaúcho } & 1 & 6,5 & 32,8 & 6,8 & 6,6 & 5,5 & 5,7 & 4,5 \\
& 2 & 6,6 & 32,3 & 6,5 & 6,3 & 5,1 & 5,0 & 4,9 \\
& 3 & 6,3 & 29,8 & 5,7 & 5,6 & 5,0 & 5,0 & 4,1 \\
& 4 & 6,7 & 29,8 & 6,5 & 6,4 & 6,4 & 5,7 & 5,5 \\
\hline
\end{tabular}

Fonte: Elaboração dos autores.

O grau de umidade também foi avaliado novamente após cada período de armazenamento com resultados variando entre 5,6 a $6,6 \%$, no tempo zero; 4,8 a $6,4 \%$ aos 30 dias; 4,3 a $6,0 \%$, aos 60 dias e 4,0 a 5,5 aos 90 dias (TABELA 2). Analisando os resultados de grau de umidade obtidos, percebe-se que os mesmo apresentam-se de forma uniforme e decrescente de maneira constante em todos os lotes durante o armazenamento.

Nas Tabelas 3, 4, 5 e 6 encontram-se os resultados da avaliação da germinação, primeira contagem de germinação, emergência e envelhecimento acelerado tradicional dos dois híbridos durante o armazenamento em câmara fria por 0,30, 60 e 90 dias de armazenamento após o hidrocondicionamento fisiológico das sementes. $\mathrm{Na}$ análise realizada para o teste de germinação (Tabela 3) e primeira contagem de germinação (Tabela 4) e emergência de plântulas em casa de vegetação (Tabela 5), os resultados mostraram variação entre os lotes de sementes do híbrido Imperial e Gaúcho pelo o teste F e com precisão experimental satisfatória. Para as sementes sem armazenamento e armazenadas por 30 e 60 dias, observa-se o lote 2 do hibrido Imperial com menor vigor, quando comparado aos demais lotes para os 4 períodos de armazenamento. Já para o híbrido Gaúcho, os resultados mostraram que não houve diferença estatística entre os lotes sem armazenamento e que o lote 2 apresentou as menores médias de germinação para os demais períodos (Tabelas 3, 4 e 5). 
Tabela 3. Germinação (\%), após $0,30,60$ e 90 dias de armazenamento de lotes de sementes de melão, híbridos Imperial e Gaúcho.

\begin{tabular}{|c|c|c|c|c|c|c|c|}
\hline \multirow{2}{*}{ Híbrido } & \multirow{2}{*}{ Lote } & \multicolumn{4}{|c|}{ Armazenamento (dias) } & \multirow{2}{*}{ Regressão } & \multirow{2}{*}{$\mathrm{R}^{2}$} \\
\hline & & 0 & 30 & 60 & 90 & & \\
\hline \multirow{4}{*}{ Imperial } & 1 & $98 \mathrm{a}$ & $98 \mathrm{a}$ & $96 \mathrm{ab}$ & $98 \mathrm{a}$ & \multirow{4}{*}{$96,78-0,174 x+0,002 x^{2}$} & \multirow{4}{*}{99,7} \\
\hline & 2 & $92 \mathrm{~b}$ & $81 \mathrm{~b}$ & $81 \mathrm{c}$ & $93 \mathrm{~b}$ & & \\
\hline & 3 & $97 \mathrm{ab}$ & $97 \mathrm{a}$ & $93 \mathrm{~b}$ & $94 \mathrm{ab}$ & & \\
\hline & 4 & $98 \mathrm{a}$ & $97 \mathrm{a}$ & $97 \mathrm{a}$ & $95 \mathrm{ab}$ & & \\
\hline $\mathrm{F}$ & & & CV $(\%)$ & 2,98 & & & \\
\hline \multirow{4}{*}{ Gaúcho } & 1 & $97 \mathrm{a}$ & $95 \mathrm{ab}$ & $90 \mathrm{~b}$ & $95 \mathrm{ab}$ & \multirow{4}{*}{$97,96-0,118 x+0,001 x^{2}$} & \multirow{4}{*}{99,5} \\
\hline & 2 & $96 \mathrm{a}$ & $90 \mathrm{~b}$ & $93 \mathrm{~b}$ & $92 \mathrm{~b}$ & & \\
\hline & 3 & $100 \mathrm{a}$ & $98 \mathrm{a}$ & $96 \mathrm{ab}$ & $97 \mathrm{ab}$ & & \\
\hline & 4 & $99 \mathrm{a}$ & $98 \mathrm{a}$ & $100 \mathrm{a}$ & $99 \mathrm{a}$ & & \\
\hline $\mathrm{F}$ & & & $\mathrm{CV}(\%)$ & 3,47 & & & \\
\hline
\end{tabular}

Médias seguidas da mesma letra na coluna não diferem entre si pelo teste de Tukey, a 5\% de probabilidade.

Fonte: Elaboração dos autores.

Tabela 4. Primeira contagem de germinação (\%), após 0, 30, 60 e 90 dias de armazenamento de lotes de sementes de melão, híbridos Imperial e Gaúcho.

\begin{tabular}{|c|c|c|c|c|c|c|c|}
\hline \multirow{2}{*}{ Híbrido } & \multirow{2}{*}{ Lote } & \multicolumn{4}{|c|}{ Armazenamento (dias) } & \multirow{2}{*}{ Regressão } & \multirow{2}{*}{$\mathrm{R}^{2}$} \\
\hline & & 0 & 30 & 60 & 90 & & \\
\hline \multirow{4}{*}{ Imperial } & 1 & $96 \mathrm{a}$ & $98 \mathrm{a}$ & $94 \mathrm{a}$ & $92 \mathrm{a}$ & \multirow{4}{*}{$94,27-0,087 x$} & \multirow{4}{*}{89,9} \\
\hline & 2 & $85 \mathrm{~b}$ & $85 \mathrm{~b}$ & $80 \mathrm{~b}$ & $84 a b$ & & \\
\hline & 3 & $93 \mathrm{a}$ & $93 \mathrm{a}$ & $95 \mathrm{a}$ & $85 \mathrm{ab}$ & & \\
\hline & 4 & $94 \mathrm{a}$ & $97 \mathrm{a}$ & $96 \mathrm{a}$ & $90 \mathrm{a}$ & & \\
\hline $\mathrm{F}$ & & & $\mathrm{CV}(\%)$ & 4,38 & & & \\
\hline \multirow{4}{*}{ Gaúcho } & 1 & $94 \mathrm{a}$ & $93 \mathrm{ab}$ & $92 \mathrm{a}$ & $89 \mathrm{ab}$ & \multirow{4}{*}{$96,32-0,072 x$} & \multirow{4}{*}{96,8} \\
\hline & 2 & $93 \mathrm{a}$ & $89 \mathrm{~b}$ & $88 \mathrm{a}$ & $84 \mathrm{~b}$ & & \\
\hline & 3 & $100 \mathrm{a}$ & $97 \mathrm{a}$ & $93 \mathrm{a}$ & $94 \mathrm{a}$ & & \\
\hline & 4 & $99 \mathrm{a}$ & $98 \mathrm{a}$ & $92 \mathrm{a}$ & $96 a$ & & \\
\hline $\mathrm{F}$ & & & $\mathrm{CV}(\%)$ & 4,35 & & & \\
\hline
\end{tabular}

Médias seguidas da mesma letra na coluna não diferem entre si pelo teste de Tukey, a 5\% de probabilidade.

Fonte: Elaboração dos autores.

Tabela 5. Emergência (\%), após 0, 30, 60 e 90 dias de armazenamento de lotes de sementes de melão, híbridos Imperial e Gaúcho.

\begin{tabular}{|c|c|c|c|c|c|c|c|}
\hline \multirow{2}{*}{ Híbrido } & \multirow{2}{*}{ Lote } & \multicolumn{4}{|c|}{ Armazenamento (dias) } & \multirow{2}{*}{ Regressão } & \multirow{2}{*}{$\mathrm{R}^{2}$} \\
\hline & & 0 & 30 & 60 & 90 & & \\
\hline \multirow{4}{*}{ Imperial } & 1 & $98 \mathrm{a}$ & $98 \mathrm{a}$ & $96 \mathrm{a}$ & $94 \mathrm{a}$ & \multirow{4}{*}{$96,26-0,394 x$} & \multirow{4}{*}{92,3} \\
\hline & 2 & $91 \mathrm{~b}$ & $72 \mathrm{~b}$ & $85 \mathrm{~b}$ & $86 \mathrm{~b}$ & & \\
\hline & 3 & $98 \mathrm{a}$ & $98 \mathrm{a}$ & $98 \mathrm{a}$ & $95 \mathrm{a}$ & & \\
\hline & 4 & $98 \mathrm{a}$ & $99 \mathrm{a}$ & $98 \mathrm{a}$ & $96 \mathrm{a}$ & & \\
\hline $\mathrm{F}$ & 2 & $* *$ & $\mathrm{CV}(\%)$ & 3,43 & & & \\
\hline \multirow{4}{*}{ Gaúcho } & 1 & $97 \mathrm{a}$ & $95 \mathrm{ab}$ & $90 \mathrm{~b}$ & $95 \mathrm{ab}$ & \multirow{4}{*}{$97,96-0,118 x+0,001 x^{2}$} & \multirow{4}{*}{99,5} \\
\hline & 2 & $96 \mathrm{a}$ & $90 \mathrm{~b}$ & $93 \mathrm{~b}$ & $92 \mathrm{~b}$ & & \\
\hline & 3 & $100 \mathrm{a}$ & 98 a & $96 \mathrm{ab}$ & $97 \mathrm{ab}$ & & \\
\hline & 4 & 99 a & $98 \mathrm{a}$ & $98 \mathrm{a}$ & 99 a & & \\
\hline $\mathrm{F}$ & & & $\mathrm{CV}(\%)$ & 3,47 & & & \\
\hline
\end{tabular}

Médias seguidas da mesma letra na coluna não diferem entre si pelo teste de Tukey, a 5\% de probabilidade.

Fonte: Elaboração dos autores. 
Com relação ao teste de envelhecimento acelerado tradicional (Tabela 6), os resultados evidenciaram variação entre os lotes do híbrido Imperial e Gaúcho segundo o teste $\mathrm{F}$ e precisão experimental satisfatória. Para as sementes sem armazenamento e armazenadas por 30, 60 e 90 dias, observa-se que o lote 2 do hibrido Imperial foi estratificado aparecendo com inferior qualidade quando comparado aos lotes 1, 3 e 4, para os quatro períodos de armazenamento.

Tabela 6. Envelhecimento acelerado (\%), após 0, 30, 60 e 90 dias de armazenamento de lotes de sementes de melão, híbridos Imperial e Gaúcho.

\begin{tabular}{|c|c|c|c|c|c|c|c|}
\hline \multirow{2}{*}{ Híbrido } & \multirow{2}{*}{ Lote } & \multicolumn{4}{|c|}{ Armazenamento (dias) } & \multirow{2}{*}{ Regressão } & \multirow{2}{*}{$\mathrm{R}^{2}$} \\
\hline & & 0 & 30 & 60 & 90 & & \\
\hline \multirow{4}{*}{ Imperial } & 1 & $98 \mathrm{a}$ & $94 \mathrm{a}$ & $94 \mathrm{a}$ & $82 \mathrm{ab}$ & \multirow{4}{*}{$94,10+0,083 x-0,003 x^{2}$} & \multirow{4}{*}{98,6} \\
\hline & 2 & $88 \mathrm{~b}$ & $78 \mathrm{~b}$ & $69 \mathrm{~b}$ & $64 \mathrm{c}$ & & \\
\hline & 3 & $93 \mathrm{ab}$ & $98 \mathrm{a}$ & $97 \mathrm{a}$ & $86 \mathrm{a}$ & & \\
\hline & 4 & $99 \mathrm{a}$ & $98 \mathrm{a}$ & $95 \mathrm{a}$ & $82 \mathrm{ab}$ & & \\
\hline $\mathrm{F}$ & & & CV $(\%)$ & 4,95 & & & \\
\hline \multirow{4}{*}{ Gaúcho } & 1 & $82 \mathrm{~b}$ & $94 \mathrm{a}$ & $91 \mathrm{a}$ & $85 \mathrm{a}$ & \multirow{4}{*}{$87,91+0,213 x-0,003 x^{2}$} & \multirow{4}{*}{98,9} \\
\hline & 2 & $85 \mathrm{ab}$ & $85 \mathrm{~b}$ & $87 \mathrm{a}$ & $85 \mathrm{a}$ & & \\
\hline & 3 & $91 \mathrm{a}$ & $96 \mathrm{a}$ & $92 \mathrm{a}$ & $86 \mathrm{a}$ & & \\
\hline & 4 & $93 \mathrm{a}$ & $93 \mathrm{ab}$ & $86 \mathrm{a}$ & $82 \mathrm{ab}$ & & \\
\hline $\mathrm{F}$ & & & $\mathrm{CV}(\%)$ & 5,26 & & & \\
\hline
\end{tabular}

Médias seguidas da mesma letra na coluna não diferem entre si pelo teste de Tukey, a 5\% de probabilidade.

Fonte: Elaboração dos autores.

Os lotes do híbrido Gaúcho mostraram-se mais vigorosos que os do híbrido Imperial, o que fica claro nos resultados do teste de germinação (Tabela 3) e no teste de envelhecimento acelerado (Tabela 6), durante todo o armazenamento em que as sementes foram avaliadas.

A agregação do hidrocondicionamento em lotes de sementes de melão permitirá às empresas produtoras a obtenção de produtos diferenciados. Embora, na maioria das vezes, o custo de sementes hidrocondicionadas possa ser mais elevado, a utilização dessas sementes pelos produtores poderá trazer benefícios no estabelecimento da lavoura, com consequências positivas na produtividade e na qualidade dos produtos (NASCIMENTO, 2002).

\section{Conclusões}

O armazenamento de sementes de melão em condições controladas $\left(15^{\circ} \mathrm{C}\right.$ e $45 \%$ UR) permite a manutenção dos efeitos benéficos do hidrocondicionamento durante 90 dias.

\section{Agradecimentos}

À empresa ISLA Sementes Ltda., pela cessão das sementes.

\section{Referências}

AMARO, H. T. R.; DAVID, A. M. S. S.; CANGUSSÚ, L. V. S.; RODRIGUES, B. R. A.; ASSIS, M. O.; VELOSO, C. S. Umedecimento do substrato e temperatura na germinação e vigor de sementes de melão. Semina: Ciências Agrárias, Londrina, v. 35, n. 3, p. 1119-1130, 2014.

ARAÚJO, P. C.; TORRES, S. B.; BENEDITO, C. P.; PAIVA, E. P. Condicionamento fisiológico e vigor de sementes de maxixe. Revista Brasileira de Sementes, Londrina, v. 33, n. 3, p. 482-489, 2011.

BALBINO,E.; LOPES, H.M. Efeitos do condicionamento fisiológico e da secagem na germinação e vigor de sementes de cenoura. Revista Brasileira de Sementes, Pelotas, v. 28, n. 1, p. 1-8, 2006.

BARBEDO, C. J.; MARCOS FILHO, J.; NOVEMBRE, A. D. D. L. C. Condicionamento osmótico e armazenamento de sementes. Revista Brasileira de Sementes, Brasília, v. 19, n. 2, p. 354-360, 1997. 
BEWLEY, J. D.; BLACK, M. Seeds: physiology of development and germination. New York: Plenum Press, 1994. $444 \mathrm{p}$.

BRASIL. Ministério da Agricultura, Pecuária e Abastecimento. Regras para análise de sementes. Secretaria de Defesa Agropecuária. Brasília: Mapa/ACS, $395 \mathrm{p}$.

CASEIRO, R. F.; BENNETT, M. A.; MARCOS FILHO, J. Comparison of three priming techniques for onion seed differing in initial seed quality. Seed Science and Technology, Zürich, v. 32, n. 2, p. 365-375, 2004.

CHIU, D. Y.; CHEN, C. L.; SUNG, J. M. Effect of priming temperature on storability of primed sh-2 sweet corn seed. Crop Science, Madison, v. 42, n. 6, p. 19962003, 2002.

COSTA, N. D. A cultura do melão. 2. ed. Brasília: Embrapa Informação Tecnológica, 2008. 191 p. (Coleção Plantar, 60).

FERREIRA, D. F. SISVAR: a computer statistical analysis system. Ciência e Agrotecnologia, Lavras, v. 35, n. 6, p. 1039-1042, 2011.

GURGEL JÚNIOR, F. E.; TORRES, S. B.; OLIVEIRA, F. N.; NUNES, T. A. Condicionamento fisiológico de sementes de pepino. Revista Caatinga, Mossoró, v. 22, n. 4, p. 163-166 168, 2009.

HAMPTON, J. G.; TEKRONY, D. M. Handbook of vigour test methods. Zurich: International Seed Testing Association, 1995. $117 \mathrm{p}$.

INSTITUTO BRASILEIRO DE GEOGRAFIA E ESTATÍSTICA - IBGE. Produção agrícola municipal. Brasília: IBGE, 2012. Disponível em: <http://www.sidra. ibge.gov.br>. Acesso em: 08 out. 2013.

KIKUTI, A. L. P.; MARCOS FILHO, J. Condicionamento fisiológico de sementes de couve-flor. Horticultura Brasileira, Brasília, v. 27, n. 2, p. 240-245, 2009.

MARCOS FILHO, J. Fisiologia de sementes de plantas cultivadas. Piracicaba: FEALQ, 2005. 495 p.

. Testes de vigor: importância e utilização. In: KRZYZANOWSKI, F. C.; VIEIRA, R. D.; FRANÇA NETO, J. B. (Ed.). Vigor de sementes: conceitos e testes. Londrina: ABRATES, 1999. cap. 3, p. 1-24.
MARCOS FILHO, J.; KIKUTI, A. L. P. Condicionamento fisiológico de sementes de couve-flor e desempenho das plantas em campo. Horticultura Brasileira, Brasília, v. 26, n. 2, p. 165-169, 2008.

MENEZES, N. L.; SILVEIRA, T. L. D.; STORCK, L. Efeito do nível de umedecimento do substrato sobre a germinação de cucurbitáceas. Ciência Rural, Santa Maria, v. 23, n. 2, p. 157-160, 1993.

NAKAGAWA, J. Testes de vigor baseados na avaliação das plântulas. In: VIEIRA, R. D.; CARVALHO, N. M. (Ed.). Testes de vigor de sementes. Jaboticabal: Funep, 1994. p. 49-85.

NASCIMENTO, W. M. Germinação de sementes de melão osmoticamente condicionadas durante o armazenamento. Revista Brasileira de Sementes, Brasília, v. 24, n. 1, p. 158-161. 2002.

. Muskmelon seed priming in relation to seed vigor. Scientia Agricola, Piracicaba, v. 61, n. 1, p. 114117, 2004.

PAIVA, E. P.; TORRES, S. B.; BENEDITO, C. P.; ARAÚJO, P. C. Condicionamento fisiológico e vigor de sementes de melão. Revista de Ciências Agrárias, Belém, v. 55, n. 4, p. 332-337, 2012.

PEREIRA, M. D.; DIAS, D. C. F. S.; DIAS, L. A. S.; ARAÚJO, E. F. Primed carrot seeds performance under water and temperature stress. Scientia Agricola, Piracicaba, v. 66, n. 2, p. 174-179, 2009.

POSSE, S. C. P.; SILVA, R. F.; VIEIRA, H. D.; CATUNDA, P. H. A. Efeitos do condicionamento osmótico e da hidratação na geminação de sementes de pimentão (Capsicum annuum L.) submetidas às baixas temperaturas. Revista Brasileira de Sementes, Brasília, v. 23, n. 1, p. 123-127, 2002.

ROSSETTO, C. A. V.; LIMA, T. M. L.; NAKAGAWA, J. Qualidade fisiológica e potencial de armazenamento de sementes de tomate submetidas ao condicionamento osmótico. Horticultura Brasileira, Brasília, v. 20, n. 4, p. 630-634, 2002.

TARQUIS, A. M.; BRADFORD, K. J. Prehydration and priming treatments that advance germination also increase the rate of deterioration of lettuce seeds. Journal Experimental Botany, Oxford, v. 43, n. 248, p. 307-317, 1992. 
